\title{
MIDWIFERY IN GENERAL PRACTICE
}

Thesis

For the Degree of M.D.,

by

GEORGE R. LIVINGSTON, M.B., C.M., 1895.

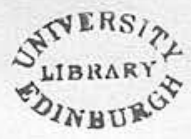


MIDWIFERY IN GENERAL PRACTICE,

or

The Consideration of Nomal and Pathological Labour, from the Country Practitioner's Point of view, with notes of the more important cases in a series of over five hunared consequetive Labours.

It is natural that, after some years have been spent in toiling in the practice of our profession, we should return to our Alma Mater and essay to win her approbation for the labours in the field of science, to which, by virtue of her previous indulgence, we have been permitted to enter. We can almost hear her voice, even when lost in the depth of a country practice, tenderly calling to each son "What use have you made of the equipment I gave you many years ago? How has it served you?"

The experience of eight and a half years -

some four years spent in junior hospital appointments and study at the larger metropolitan hospitals and over/ 
over four years in general practice. Surely a good opportunity! Has the result in the further education of the child of the alma mater, been such as to win the much envied and valued reward?

Undoubtedly a great mass of material must have been obtained, from which a thesis might be composed. But from this mass of material a subject has to be chosen and this, in itself, is no easy task.

Owing to the nature of country practice, accurate original research, dearly as one may love it, is out of the question. For accurate scientific study scientifically equipped laboratories are required. and these are only to be found in large centres. But as Dr James Ritchie stated, when referring to the man in practice, in his presidential address to the Edinburgh Obstetrical Society on I2th November, 1902, "He (i.e. the general practitioner) may not have time for original scientific research, but he may do all his work in a thoroughly scientific spirit." Acknowledging, then, that original scientific research cannot supply a subject for a country practitioner's thesis, we may still hope that the scientific spirit may be apparent in his work. We find that two factors must influence the choice/ 
choice of his subject. In the first place selfish motives must play an important part. All his reading and study, broken up and disjointed as it must of necessity be, will run in subjects in which his greatest interest lies and should be so directed that it may be of every day value to himself and calculated to render more effective the treatment of his future cases. Such considerations will undoubtedly render a thesis less interesting from a purely scientific point of view. In the second place for the sake of convenience, the subject of a thesis should be limited at all events to one branch of our profession. And, naturally, one turns to that branch of the profession in which one is constantly employed, and for which one feels one has some natural aptitude, and in which one has some reputation as a successful practitioner, at all events if one may judge from the increasing number of calls made upon one's professional skill in this department.

To find a subject formy thesis, I have therefore to turn to Midwifery. To be a successful country doctor, it is absolutely necessary to be an expert obstetrician. And it is therefore because/ 
cause I feel that in the subject of Midwifery I am more at home that I have decided to take up for the subject of my thesis something belonging to this art so ancient. And because I feel that the question of results in our (i.e. country practitioners)treatment of women during childbea, of late so constantly brought betore the medical profession, should receive attention from one who is in the thick of country practice, and because I find on going carefully over the medical joumals of recent years that no general practitioner appears to have published his results, and there are in the Jourmals, many references to the general practitioner's failure. And because I feel that in estimating the causes of the "deplorable results" with which the country practitioner is credited, the obstetricians who have lately drawn attention to the subject have not fully grasped all the causes at work in bringing about such a state of affairs.

But this branch of medicine is wide, and again one is face to face with the question, "What is your subject?" Is it to be a dissertation on Midwifery in general? How is the subject to be treated? To take up one particular branch in Midwifery is/ 
is out of the question. General practitioners could not have a sufficient number of cases to render it practical, and I have thought that the most profitable study for myself and at the same time not uninteresting subject for a Thesis would be the consideration of the series of midwifery cases I have attended since graduating M.B., C.M., in 1895 .

I find on going over my notes, that since that date I have attended over five hundred labours and my subject therefore resolves itself into "Midwifery in General Practice, or the Consideration of Normal and Pathological Labour from the country Practitioner's point of view, with notes on the more important cases in a series of over five hundred Consecutive Labours."

This subject is rendered, at all events to myself, aditionally interesting in the light of recent papers in the Edinburgh Medical Journal by the late Dr Milne Murray and also one by Dr Dewar. The late Dr Milne Murray's paper may be taken as a fair representation of the prevailing opinion which specialists in this branch of the profession hold regarding midwifery in general practice. Dr Dewar's paper/ 
paper is a report of work actually done in a large general practice. And in this thesis I shall aim at giving a detailed report of the more interesting cases which I have been called upon to treat.

All cases so reported, and all cases in the series of cases referred to, are cases in which I attended the labour throughout. I will have occasion to refer to several cases which I have seen with practitioners in neighbouring villages during the last three years; but these are not included in the 500 cases; nor are cases of obstetrical operations (embryotomy, etc.) seen at the Rotunda but in which I took no part in the management.

It is perhaps necessary that I should state at this stage that my series of cases includes cases attended in Edinburgh, in rifeshire, Central Perthshire, in Dublin, in Howth (Ireland) and surrounding district, and in the town of Dumfries and in the surrounding country included in an area with a ten mile radius from Dumfries. It may further be stated that the cases are drawn from all classes of society, paupers (the earlier cases were mostly from this class), labourers' wives, clerks, lawyers, bankers, and ministers' wives. It is therefore claimed/ 
claimed for this series that they are a fairly typical representation of a general practitioner's cases in a mixed country practice, and representative of the ordinary run of midwifery cases attended by general practitioners throughout the country. I shall also try to show what I believe to be the chiet causes of the "deplorable results" of private practice.

In considering a large number of cases the question at once arises, what method of classification is to be followed, and how are the particular cases reported in full to be selected? A mere chronological history of the cases would be wearisome and uninteresting. It is perhaps natural that the early lecture room method of considering the subject should suggest itself as the most suitable for the purpose in view. I therefore propose to group my cases under:

I. Normal Labours:

1. Unaided

2. Membranes artificiäly ruptured.

3. Forceps.

4. Grave complications in Puerperium, Puerperal Insanity. 
II. Praetematural Labours:

1. Pelvic.

2. Transverse.

III. Complex Labours:

1. Placenta Praevia.

2. Retained Placenta.

3. Eclampsia.

IV. Foetal Complications:

1. Prolapse of Cord.

2. Twins.

3. Anencephalus. .

\section{P A R T I.}

Report of Principal Cases in the Series of Five Hundred Labours.

I. Normal Cases:

1. Unaided Cases: Under this heading are included cases in which the waters "broke" spontaneously during labour, where practically no support was required for the perineum, and at most only an enema was required by way of active interference, to/ 
to hasten delivery. In these cases the presence of a practitioner could have been dispensed with, but no doubt greater comfort was secured for the patient. Throe cases demand a few remarks, as they were of somewhat unusual interest. Two were "Street Deliveries". In the third case the child was born in the lift at the Rotunda. Hospital between the first and second floors.

My first "Street Deliv ery" occurred in an outof the way part of Dublin; but in a thoroughfare much frequented by people on their way to their work in the morning. The woman was on her way to work about $6.30 \mathrm{a} \cdot \mathrm{m}$. when 1 abour set in. I was at the time resident in the Rotunda hospital, and, al though I was not on duty for extern cases, I was called up, as my bedroom was close to the entrance. I found a policeman waiting and I was conducted on a car to the scene of action to find the campaign practically completed in the presence of four stalwart policemen and a crowd of about a couple of hundred persons. The poor woman was lying on the pavement, and half smothered cries coming from under her petticoats informed me that the child was alive. My first glance at the woman convinced me that she was/ 
was not bleeding. I therefore got a few of the shawl women, who are always much in evidence in Dublin crowds, to stand round and hold their shawls up to form a screen. This made a fairly satisfactory, though roofless, lying-in chamber. On passing my hands under the woman's skirts I found, on feeling for the cord, that it was torn across. I removed the child and found there was no bleeding from the cord. I however placed a ligature upon it. It was interesting to find that the ladies who were kind enough to lend their shawls were availing themselves of their privileges as onlookers and one announced to the crowd behind her, "It's a boy." I had formed the opinion that the woman's uterus was well contracted, al though I could not feel it distinctly through her clothes. Through some mistake the ambulance had not arrived, and as I understood the police ambulance had been ordered out, I had not brought a hospital stretcher with me. As the patient appeared to me to have lain long enough on the pavement I got the police to get a passing cab and with their assistance lifted the patient in and conoucted her to hospital. After getting her sarely to bed I washed up the external genitals/ 
genitals very thoroughly and then expressed the placenta from the vagina. I then gave a vaginal douche and for the first three days she had a regular vaginal douche. She made an uninterrupted recovery and her temperature was normal throughout. The child also did well.

My second "Street Delivery" occurred within half a mile of the Rotunda Hospital. The woman, a multipara, was in the havit of going to the hospital to be confined, and was actually on her way to the hospital when labour set in. It was late in the afternoon and I happened to be on duty in the hospital at the time. I took two students, who happened to be in the hospital, to assist me. No attempt had been made to move the woman. In this case also the cord was torn across and there was no bleeding. The same procedure was gone through and we placed the woman on the stretcher we had brought with us, and two policemen kindly carried it back to hospital. I had often heard that labour in Ireland was under police supervision, but I had not realised it. In hospital I washed the patient up and gave a vaginal douche. This patient also made an uninterrupted recovery.

The/ 
The third case referred to was a case of miscarriage between the sixth and seventh months. I was called by the porter to see a patient, in the entrance hall, who was apparently in labour. I found the patient was a lady, apparently in quite good circumstances. She explained that she was about six months gone, that she had been out shopping and labour came on, and as she was not far from the hospital applied for admission. I instructed the porter to telephone to the sister of the labour ward and I assisted the patient into the lift. The pains were very severe and I had some difficulty in getting her into the lift. Somewhere between the first and second floors the foetus was borm. I found two nurses waiting with a stretcher, and we removed the patient to a private ward. After she had been undressed, she was carefully washed up and a vaginal douche given. She made an uninterrupted recovery. Another case which naturally falls under this heading was of some little interest. I had been engaged to attend a pultipara and was duly called when labour set in. I arrived and on examination found the os fully dilated, and the head well down on the perineum, but not bulging it to any great extent during the pains. As the parts appeared pretty / 
tight I sat, as I generally do in such cases, on a chair at the side of the bed and drew the hips of the patient up close to the edge of the bed and placed the patient's body across the bed, so that her head lay on the opposite side of the bed. This is not an orthodox text book position, but I have found this position of great service in "saving a perineum" and in applying forceps when single handed. Suddenly the patient gave a tremendous yell and then wi thout warming, the baby was shot across my knees, landing upon the floor with a thud. During its passage from the vulva to the floor it touched nothing; it was simply shot from the woman like a cannon-ball and passed over my knees with the swiftness of lightning.

I found the cord was tom across about three inches from the body and there was no bleeding from it. This well illustrates the extraordinary and powerful force which the uterus possesses.

Probably about $80 \%$ of my cases come under this heading and these were all cases in which an intelligent nurse could have conducted the labour.

(2) Membranes Artificially Ruptured : In cases/ 
cases where I found on examination that cervical dilatation was complete, I ruptured the membrane For this purpose I have always used a small exploring needle, which I carry in my pocket case. In view of the great septicity in general practitioners midwifery practice, it may be fervently hoped that the time honoured hairpin may fall into disuse for this purpose. Doubtless a hairpin could be boiled, but it does not seem to be so treated before use for this small operation. Most practitioners carry a pocket case which contains some instrument suitable for the purpose, and such an instrument is more likely to be sterile than a hairpin. And, al though the first gush of waters will wash away any organism introduced by the hairpin, it would be well, even in so simple a detail, if a more scientific procedure were adopted, especially as, at the present time, even general practitioners either boil or cleanse their instruments with antiseptics.

3. Forceps Cases: In twenty-six cases, or slightly over $5 \%$ of the whole series of 500 cases, labour was terminated by the use of forceps. There were no matemal deaths in my forceps cases, and one child was still born. In this case labour should have been terminated sooner, the foetal heart was quite/ 
quite vigorous and distinct early in labour. Having been called to the case too early, and as the patient was a healthy multipara and there being no indication for the application of forceps, when I first saw the patient, I left - having some other rather urgent professional matters to attend to. It was sometimes before I could again see the patient, I was surprised to find, on my return, that the woman had not delivered herself. She had been over six hours in the second stage and was much exhausted. I applied forceps and delivered her at once. The child's heart was beating very feebly I made every effort to start respiration, but the child died.

The above case well illustrates the difficulty and anxiety which practitioners have to face in districts where a doctor is single handed and has no friendly colleague whom he can get to act for him when he has more than one case on hand requiring immediate attention. It is not uncommon to get a message to go to a confinement four or five miles in one direction, and before you have dressed get another message requesting your professional services at another case four or five miles in quite an opposite/ 
opposite direction. I suppose it is the experience of most medical men that confinements come in a rush, and I believe this largely accounts for the very high percentage of foreeps cases. Country doctors are in a hurry at many of their midwifery cases, especially where they have no one to fall back upon and their own convenience becomes an indication for the application of forceps. Indeed, a fellow-practitioner in a country area told me, when conversing upon this subject, that the only question he asked himself was whether the forceps could be applied? Was the labour sufficiently advanced to enable him to apply the forceps? But I believe that had I taken as an indication for forceps the fact that I could not remain with my patient, who was so far advanced in labour a living child would have been obtained, the death of the child being in my opinion due solely to the protracted labour.

The following table shows the total number of forceps cases primiparae and multiparae, with their ages. 
Primipara Age. Multiparae Age.

\begin{tabular}{|c|c|c|c|c|c|c|}
\hline Case & 1 & & 22 & Case & 1 & 38 \\
\hline$"$ & 2 & $\mathrm{R}$ & 40 & " & 2 & 25 \\
\hline$"$ & 3 & & 25 & $" 1$ & 3 & 36 \\
\hline$"$ & 4 & ${ }^{*} \mathrm{R}$ & 41 & "1 & 4 & 38 \\
\hline$"$ & 5 & $\mathrm{R}$ : & 38 & $"$ & 5 & 40 \\
\hline " & 6 & $\mathrm{R}$ & 42 & $" 1$ & 6 & 31 \\
\hline$"$ & 7 & & 32 & $"$ & 7 & 36 \\
\hline 11 & 8 & & 30 & $"$ & 8 & 38 \\
\hline$"$ & 9 & I R & 30 & " & 9 & 40 \\
\hline$" 1$ & 10 & $\mathrm{R}$ & 33 & " & 10 & 39 \\
\hline$" 1$ & 11 & $\mathrm{R}$ & 40. & $"$ & 11 & 28 \\
\hline$"$ & 12 & & 28 & & & \\
\hline " & 13 & $\mathrm{R}$ & 30 & & & \\
\hline$"$ & 14 & & 28 & & & \\
\hline$"$ & 15 & $\mathrm{R}$ & 33 & & & \\
\hline
\end{tabular}

In those cases marked R., that is in No.2, $4,5,6,9,10,11,13,15$, the perineum was ruptured. In Case No.4 marked * I saw that it was hopeless to save the perineum and I therefore made two lateral incisions. After labour I stitched these incisions and the result was excellent. In case No.9, marked ${ }^{l}$ there was a very small laceration/ 
tion, so small in fact that it would not have been necessary to stitch it, but a severe pain coming on forced the shoulders suddenly upon the perineum and it was split almost to the rectum. This case impressed upon me the necessity of watching the passage of the shoulders as carefully as the passage of the head. It was disappointing to find the perineum split in a mement when I had spent nearly an hour in trying to deliver the head so that I might save the perineum.

Among the multiparae I had no lacerations, but a very large percentage had been previously ruptured and many of them had evidently not been stitched. Later on I shall have to refer to this fact in considering the results obtained by general practitioners in midwifery.

4. Grave Complications in Puerperium: Case of puerperal Insanity.

In July 1900 I had occasion to see a multipara during the latter part of her sixth pregnancy. I noticed that she seemed to have changed somewhat. She took little or no interest in her household duties. Her children and husband seemed of no interest/ 
interest to her, and as a rule she was a most exemplary wife and mother. The change in her mental condition was, to my mind, so marked that I spoke to the husband about it. He had not noticed anything peculiar about her, but when I mentioned the matter thought she had changed somewhat. She was suffering from very troublesome constipation, and I therefore put her upon treatment to counteract this, and prescribed a tonic and mild sedative for use at night, as she had some difficulty in obtaining sleep. There was no family history of insani ty .

Her confinement came off at its expected time, and there was nothing to attract attention. She had a very easy labour, there was no excessive haemorrhage. Very soon arter the confinement it was very evident to the most casual observer that the patient's mental condition was very far wrong. She lay all day with a rapt expression upon her face, but refused to enter into conversation and would not answer any questions I put to her during my visit; but as a rule I when I was leaving the room she shouted out that she was "damned", but on my turning back to enquire into the mattex, she refused to answer/ 
answer my questions and lay smiling in the same silly way. A considerable degree of fimness had to be exercised in the matter of feeding her. If her mental condition was unsatisfactory from the first, her bodily condition soon began to give me some anxious thought. She very rapidly emaciated. She had no rise of temperature, and the lochia although perhaps somewhat scanty, was otherwise normal. Her tongue was thickly coated and furred, and it was with great difficulty that her bowels could be got to act. Her urine was very high coloured and scanty. There was no albumen, but phosphates were present in large amount. It was only by the exhibition of large doses of Potassium Bromide and Chloral Hydrate that any sleep could be obtained. For about ten days this state of matters continued, when she seemed to improve somewhat. She seemed brighter and answered any questions I put to her in a leisurely manner. I began to hope that my patient would now improve. She was now in her third week. Early one moming I was hurriedly summoned to see her, as she had made several attempts to destroy the baby and had attempted to throw herself over the quarry head, near where she lived. When I saw her, she was quite maniacal, and only/ 
only controlled with the greatest difficulty. She was dancing about and shouting and singing. It was quite out of the question to keep her at home, as her husband and friends could not afford to remain away from their work, and they were not in a position to employ trained attendants. I therefore arranged for her removal to the Chrichton Royal Institute, where she was put under treatment for three months. At first her progress was very slow, and she was very troublesome; but uitimately she made a good recovery. For the last two years she has been in good healtin, and about six months ago passed through another confinement wi thout any mental disturivance, and is at present in very good neal th. 
II. Praetematura.I Labours

1. Pelvic Presentations: These are stated to occur about once in thirty labours or, if premature births are excluded, once in sixty labours. It is curious, however, that in my series of 500 cases I have only had two breech cases, apart from cases where it was necessary for me to employ version. This bears out a point which I have often emphasised namely, that we can form little idea of what we are to meet with in practice from the study of statistics. I have, however, been askea on several occasions by neighbouring practitioners to deliver pelvic presentations. And from enquiries I have made among neighbouring practitioners, it would seem quite uncommon to have so few.

In my own two cases both occurred in multiparae and the labours were easy and there was no difficulty in either case in delivering the after-coming head. Both were living chilaren.

2. Of Transverse or cross birth I have had three cases.

Case I. My first case occurred in a remote part of Perthshire. On palpating the woman's abdomen I could make out the head of the child lying over to the/ 
the mother's left, the back of the child being to the front. On examining per vaginam I found a large sausage shaped bag of waters, the os being well dilated. The pains were regular and fairly strong. T anaesthetised the patient deeply and tumed. The pelvis was roomy, and the operation easy. In this and in a.1 cases in which I have had to turn, I have placed the patient upon her back across the bed. The placenta was expelled in about ten minutes. Both mother and child did well.

Case II. My second case occurred very shortiy after I settled in Dumfries. I was called to see the patient because she was in labour and she thought something was wrong. On examining her by abdominal palpation and also by vaginal examination I found that the presentation was transverse. The os was not dilated and any uterine contractions were slight. I had the bowels freely moved by an enema and then a.tempted to rectify the position by external version. I thought I was successful in this, and placed a pad on either side of the uterus and applied.a binder. Two hours later, however, I found labour had fairly set in. The os was well dilated and I could feel per vaginam a long sausage shaped bag of membranes almost presenting at the vulva and I/ 
I could make out the arm presenting. My preliminary manoeuvres had evidently not been successful. I at once placed the patient deeply under chloroform and delivered by intermal version. In this case the operation was considerably more difficult than in the previous case reported. I was, however, successful in getting a living child. Both mother and child did well.

Case. III. The third transverse birth which I have been caljed upon to treat occurred in a woman of the lowest class in the poorest quarter if Dumfries. She was an underfed puny, miserable specinen of humanity. She belonged to that class who never apply to a doctor unless something has gone wrong. A neighbour who was attending her was alarmed at the length of time the woman had been in labour, and fearing that something was wrong, thought it right to call in "skill" . On examination I found the membranes were not ruptured. The os was fully dilated and I could make out the arm presenting, the chila's head boing to the mother's left and the back to the front. Having placed the patient deeply under chloroform I delivered the child by intermal version. After delivering the child/ 
child I found it was a case of twins. This I had not suspected. As there was most persistont and somewhat severe haemorrhage, I ruptured the membranes and delivered the second child by internal version also. Both children were males. The second had a very marked harelip. The puerperium was uneventful and both children did well.

\section{Complex Labours:}

1. Placenta Praevia: of this very serious complication I have had three cases. In my first case I got a living child and the mother did well. In my second case I lost both mother and child, and in my third case I lost the child.

My first case occurred in Ireland. The patient was a multipara of about 37 . She had reached. full time and wakened up one night to find she was bleeding, and she and her friends were naturally greatly alarmed. I was hastily summoned. I found labour had set in, and on vaginal examination I found the os dilated sufficiently to admit of two fingers, and I could feel the edge of the placenta and also with the tip of my finger I could feel the membranes. The haemorrhage was moderate but very steady, and I could not detect any variation in its quantity/ 
quantity during or between the pains. Having put the patient under chloroform I brought dow a foot and slipped a loop of gauze round it. Upon this I from time to time made traction. That such a line of action is most effective was well illustrated. Whenever some bleeding occurred I simply pulled on my gauze $100 p$ and the haemorrhage stopped at once. The pains increased very rapidiy in frequency and severity, and in about an hour's time the child was borm. It was only after prolonged efforts to induce respiration that the child was brought round: But in the end, both mother and child did well.

My second case occurred in a woman to whom I was called early one moming, a week or two after I came to Dumfries. The husband, who came for me, informed me that his wife was up to full time, that labour had set in, and that she was bleeding profusely. He further told me that she had had two or three fairly severe bleedings during the last month or two. On entering the house, which was a miserable two-roomed habitation, I found the woman on the floor half kneeling against a chair. The whole floor was carpeted with blood clot, and I had literally to splash through a sea of blood to reach hex./ 
her. I got her into bed wi thout loss of time, only taking time to cleanse my hands and the external genitals. I examined her and found the condition one of central placental presentation. I placed the petient across the bed in the dorsal position and, having anaesthetised her, passed my fingers through the placenta, secured both feet and brought them down. As the case was an exceedingly anxious one, I delivered at once. The child was dead, al though I delivered with great rapidity. I could not, however, attempt to resuscitate the child as all my attention was required for the mother. The uterus was well contracted and there was no haemormage after delivery wos completed. I gave $1 / 100 \mathrm{gr}$. Digitalin hypodermically, and about 20 minutes later $1 / 100 \mathrm{gr}$. of strychnin: hydrochior. The patient's pulse improved very markedly, so much so that al though I had brought my transfusion instmuments, I did not transfuse. This I had cause to regret. I remained about two hours with my patient, and as my own house was quite close I went home. When I left the patient was Iying comfortably. Her pulse had falien to 90 and had greatly improved in character. Her breathing was/ 
29.

was regular and her respirations numbered 16 per minute. She complained of being tired, but otherwise seemed quite comfortable. I was called to see her about four hours later, and on my arrival found that she was dead. It appears that she steadily improved after I left and shortly before I was summoned wished to pass her water. She sat up in bed with the intention of getting up to do so when, without even a cry, she dropped back dead. I found on examination that there had been no haemorrhage since I left her.

My third case of placenta praevia occurred in the end of 1903 and the patient, a multipara, was the wife of a quarryman living about four miles from Dumfries. Her husband came for me and told me she was bleeding, and they thought in labour. On enquiry I found that she was about seven, or seven and a half months gone; and she had had one or two previous bleedings, for which she had not sought advice. On my arrival I found, on examination per vaginam, that I could feel a stringy mass right over the os, which was sufficiently dilated to admit two fingers. Placing the patient under chloroform, I passed two fingers through the placenta and secured a) 
a. foot, which I brought down, and to which I attached a loop of gauze and upon this I made occasional traction. Labour progressed rapidly and was completed in about an hour, and during the whole time I was able to control the haemorrhage with great ease. The woman made a good recovery, and the puerperium was uneventful. The child was lost; but even had it been bom alive, its chances would have been small, as premature children in that class of live cannot get the attention necessary to rear them.

\section{Retained Placenta. Only once have I} met with a case of retained placenta. This condition occurred in a multipara and after massaging the fundus uteri and trying my external manipulations to induce the placenta to leave the uterus, I found it necessary to introduce my hand into the uterus and separate the placenta, which was in part firmly adherent. I afterwards gave a hot creolin intrauterine douche. The patient had quite a normal puerperium.

3. Eolampsia. When acting as locum tenens in a country district in Ireland, during the early spring of 1898, I was called to see a patient who was/ 
was said to be in labour and who was stated to have taken a fit. On my arrival I found the patient had had three distinct fits. The patient belonged to the poorer peasant class; and, a.l though a wellformed woman, was underfed, and indeed appeared to be half starved. She had been under treatment at a country dispensary for indigestion, from which she had suffered from the early months of her pregnancy. She did not appear to have obtained much relief from the treatment adopted; but her food had been scanty and unsuited to her condition. The fits were described to me by the neighbours in attendance. The patient had complained of vague pains for some days and thought she would not get over this confinement, which was her sixth. She had also suffered from severe headache and her friends had noticed that she was very gloomy and depressed. Labour set in and the pains became fairly strong and regular. A medical man had not been engrged and it was not the intention of the patient to have a doctor, as she had never had one in any of her previous confinements. The neighbours, who were with her, first noticed twitching about her eyelids and face. The head rolled from side to side, and the arms were thrown from side to/ 
side, and the whole body seemed to be contorted. The breathing, they said, then became very heavy, the convulsive movements at the same time passing off. The patient lay breathing very heavily and a.pparently unconscious; at 2.11 events they said they were unable to rouse her. As they were all alarmed they sent off for the priest and the doctor When I arrived I found the priest had been, and had left, after having administered the last rites of his church to the unconscious woman. The patient, when I first saw her, was quite unconscious, the pupils contracted, and the conjunctival reflex gone. The breathing was stertorous. While I was listening to the history of the case as told by the neighbours, the patient took a fourth fit and I was therefore able myself to observe the sequence of its various phases. The fit seemed to commence with some twitching about the mouth, but the involvement of the other face muscles followed so rapidly that It was not easy to say in which muscles the fit commenced. The expression became that of a ghastly grin of a person apparently making heroic but fruitless efforts to speak. The eyes were rolled up and the white showing under the lids gave the patient an even more unpleasant expression. The face and/ 
and neck were very morkedly cyanosed. The arms were brought violently across the chest, and the legs flexed and extended with great rapidity. The breathing became stertorous and the patient remained unconscious. I had never before seen a case of eclampsia, and some seventeen miles from any medical man whose advice, or assiștance, I might wish, the horror of the situation was uppermost in my mind for the time being.

Without loss of time I administered $\frac{1}{4} \mathrm{gr}$. Morph. Sulph. hypodermically. Within thirty seconds the patient was lying absolutely still and comatose. I must confess some apprehension arose in my mind as to the wisdom on the treatment I had adopted. It was, however, the treatment employed in the Rotunda at the time, and much had been written in favour of it in the medical journals of that date. Urine had apparently been passed involuntarily, but as the bed was wet from discharges I passed a catheter and found the bladder empty. Later I obtained a sample and found it was loaded with albumen.

On making a vaginal examination, I found the os fully dilated, the head well down in the pelvis. I mptured the membranes, and in about five to ten minutes the head was born, and with little assistance the/ 
34.

the body followed. The mother lay deeply comatose breathing stertorously, and I therefore attenced to the child.

The child's heart was beating very feebly and irregularly and it made no efforts at respiration. Having cleared out the throat, I proceeded to induce respiration by Schultze's method. After about quarter of an hour the child began to give evidence of life, and I was able to hand it over to one of the neighbours. During the time I was occupied in resuscitating the baby the mother lay in the same comatose condition in which she had been when the birth was completed. Judging from the small amount of discharge from the vulva I had concluded there was no haemorrhage going on during the time I was occupied with the baby, and on feeling the fundus through the abdominal wall I found the uterus well contracted. The least possible pressure was sufficient to express the placenta. I then washed the woman uo and having got such clean articles as her poverty stricken surroundings allowed, I placed them undermeath her. By the time I had finished. the patient was breathing less stertorously. Her pulse was 80 and quite steady, and I began to congratulate myself on so happy an ending to a very. anxious/ 
35.

anxious case, and was preparing to leave the house, when without any warning the whole body was thrown into convulsions. I again administered $\mathrm{gr} \cdot \frac{1}{4}$ Morph.Sulph. Within 30 seconds all convulsive movements had ceased, and the patient lay deeply comatose, and for two hours she remained in that condition, it being quite impossible to rouse her. After that it was possible to rouse her, but she was very stupid, and it was some days before the mental condition was quite normal. Patient improved steadily and little treatment, beyond that which was necessary to keep her bowels acting regularly, was required.

Case II. My second case of eclampsia came under my observation when acting for a doctor in the vicinity of Dublin during the spring of 1898 . It is somewhat curious that within a comparatively short time in a limițed area I should have met with two cases of eclampsia, which in Ireland is a somewhat rare complication. The patient, a multipara, was one by whom the doctor, for whom I was acting, had been engaged to attend. The only information I had from himself was that her labours were always easy, and the woman who would attend to her was a very decent and reliable person, and would not send for/ 
36.

for me before it was necessary. I did not myself see the patient until called, when she was in labour. I was called to see the patient early one morning and on my arrival found the patient walking about. The pains were coming every few minutes and indeed, hardly seemed to leave her. I persuaded the patient to get into bed, and on making a vaginal examination I found the os fully dilated. I ruptured the membranes.. The pains became quiescent for a short time and then began again, with renewed vigor. I had been in the room somewhere about an hour when I noticed the patient's expression change. Up till that time there had been nothing to attract attention or lead one to suppose the confinement would be other than normal. She was a well developed woman and appeared to be of a heal thy and sound constitution. This was her fourth pregnancy. The eyes opened widely, and her gaze became fixed. For the moment it appeared as if something behind me had attracted the patient's attention and she seemed surprised and about to speak; but the expression rapidly changed to one of anxious horror, the head was rolled from side to side on the pillow and the arms crossed and recrossed over the chest. The convulsive/ 
37.

convulsive movements rapidly affected the whole of the muscles of the body. The pupils were widely dilated and the conjunctival reflex gone, and the patient quite unconscious. As the convulsions ceased, the breathing became stertorous, the patient remaining in a state of deep stupor. The child's head had now reached the perineum and the uterine contractions were strong and almost constant. As it was quite evident that nature unaided would very rapidly complete the labour I did not apply forceps, and indeed the child was born before I could have applied them. Just before the head was born the woman had another fit. I was just in the act of injecting Morph. Sulph. gr. $\frac{1}{4}$ subcutaneously when it gommenced. The fit was less severe and appeared to last a shorter time than the previous one. And the patient passed into a state of deeper stupor. The termination of the labour was exceedingly easy. The child, a healthy male, gave no anxiety and the placenta came away from the vagina with the least possible pressure on the fundus uteri. There was very little haemorrhage, and the uterus remained well contracted. The patient was only under my observation for the next ten days, but her condition during/ 
during that time was quite satisfactory.

Case III. While acting during the summer of 1898 for a doctor in a village of Perthshire, I was called to see a woman advanced in pregnancy who was stated to have had a fit. I saw the patient as soon as possible and found her walking about the room in a somewhat excited state. She had taken a violent prejudice against her husband and would not let him enter her room. She was a well-made, muscular woman and had not the appearance of a patient one would associate with hysteria. From her friends I found that this was her third pregnancy and that according to her calculations she was about a fortnight off full time. Her wild and excited manner, and her rambling incoherent conversation, at once attracted attention. After some coaxing she consented to go to bed. On removing the clothes and inspecting the abdomen I found the usual signs of advanced pregnancy. On palpating the uterine tumour I found the breech of the child was uppermost with the back of the child to the mother's left, and the head could be palpated low down in the pelvis. The foetal heart could be heard beating vigorously midway between the umbilicus and left superior anterior spine. I could. not/ 
not make out any uterine contractions. On examination "per vaginam" I found the os barely admitted the tip of the finger. The fit was described to me by the patient's relations. Up to the time of the seizure she had been in good health and they had noticed nothing unusual about her. While sitting in her chair, without any warning, she suddenly became stiff and her eyes fixed. She then began to "work" with her arms and legs and rolled her head about. The whole seizure lasted only a few minutes, and during the attack she appeared quite unconscious. She was quite black in the face, they said, and her breathing was very heavy and laboured. Her breathing gradually became more hatural and she regained consciousness, but had remained in the excited state in which I saw her. Urine had been passed involuntarily and I was therefore unable to obtain a specimen of it at this time. I did not feel justified in forming a definite diagnosis of eclampsia. The patient was an exceedingly well made buxom country woman, and while it seemed from her excited appearance that she might possibly be suffering from hysteria, yet she did not seem a likely subject for such a condition, and I could make out no previous history of anything pointing to hysterical/ 
ical tendencies. Indeed, from the history I obtained from her friends, she seemed, when in her usual health, an exceptionally placid mortal. I ordered a sharp purge and prescribed a mixture containing chloral and bromide to be taken every two hours. I also gave directions that as soon as possible a specimen of her urine should be obtained and sent to me. A specimen was sent me late in the evening and I found it almost solid on boiling. I saw the patient later in the evening and she looked much better and said she felt all right and seemed to think her friends had been making an unnecessary amount of fuss. She still seemed to cherish some grudge against her husband. I could not help thinking that I had to deal with a case of insanity of pregnancy. Her pulse and temperature were normal. Shortly before retiring I was called again and found the patient in a typical fit. When I entered her bedroom she was lying twitching all over. The head was rolled about from side to side, the muscles of the arms, trunk and legs twitching very markedly. The pupils were somewhat contracted, and did not react to light. The conjunctival reflex was absent. The fit gradually passed off and the breathing became stertorous. The patient's friends/ 
friends said she had had several fits before my arrival. I at once administered $\mathrm{gr} \cdot \frac{1}{4}$ of sulphate of morphia hypodermically. Within a few minutes a.l signs of a fit had passed of $f$ and the patient lay apparently sound asleep, her breathing perfectly regular, but I could not rouse her in any way. The patient's house was at the foot of the doctor's garden, and I therefore went home to make arrangements for spending the night at my patient's house. on my return, about ten minutes later, I found labour had not only set in, but was nearly completed. The child, a healthy male, was born shortly afterwards, the placenta following in about fifteen minutes. There was practically no haemorrhage. The patient remained in a state of semi-coma for about 24 hours, during the earlier part of which she could not be roused, later she could be roused but at once dropped off to sleep. For a few days she remained in a drowsy, sluggish condition, which gradually passed off and she eventually made a good recovery. She was under treatment for albuminuria for some weeks, but this gradually cleared up. 
Case IV. Very shortly after commencing practice in Dumfries, I was called to see a patient who was said to be about seven months pregnant, and who was stated to have taken fits. I saw the patient shortly arterwards. I found her laughing and crying in a hysterical manner. From the description given by the friends, the patient seemed to have had an eclamptic fit. The swollen condition of the lower eyelids and lips at once attracted attention. I could not obtain a specimen of ner urine, as it has been dassed involuntarily during a fit. Later, I found it was very scanty in amount and contained albumen. I prescrived a mixture of Chioral and Bromide. I found from the enquiries I made of her Iriends, that this was the second pregnancy; that the first, some eighteen months vefore, ended in a miscarriage at about the fourth month, and apparently she had a fit then. I saw the patient occasionally during the evening. She was duil and drowsy and was only roused with difficulty. Her pupils were normal and the conjunctival reflex was present. I injected quarter of a grain of sulphate of morphia hypodermically and saw patient about five hours later. Her condition was the same. She had had no fits in the interval/ 
interval. There were no signs of commencing Iavour and I could not satisfy myself that the foetus was alive. Shortly arter my visit, fits commenced. They were not at first so severe as those which had occurred previously, but increased rapidly in frequency and severity and became almost constant. I was sent for and on my arrival found patient had been delivered of a six months foetus, placenta and membranes having come away also. There was a fair amount of discharge, but it was not excessive. The patient was quite unconscious; the pupils were contracted and the conjunctival reflex was gone, the race and neck were very markedly cyanosed, and her breathing was stertorous. This condition lasted some hours, wut passed off gradually. The convalescence was slow, wut the patient made a good recovery.

Gase V.: This case was of very great interest in many respects. In the first place, the patient was the woman whose condition was described in Case IV. She was a strong, healthy woman, and before her previous attack, had never known a day's ill health. If the history I obtained from her mother, who was an intelligent woman, was correct/ 
correct, she had a fit during a miscarriage between the fourth and fifth months. She was not attended by any doctor at that time, as the whole thing was over so rapidly that they had no time to send for one.; and the ouservations may or may not have been correct. In her second pregnancy, she miscarried between the sixth and seventh month and I myself attended her and I have described her condition on the various occasions upon which I then saw her; and sixteen months later, I was called to attend her during the temination of her third pregnancy. This is exceedingly interesting, for in her I had a patient who was suffering from eclampsia and had had an attack in one, and possibly two previous pregnancies.

I was called to see her about $7.30 \mathrm{p} \cdot \mathrm{m}$. on 14th April, 1903, and saw her soon arterwards. She was quite conscious when I saw her, but heavy and drowsy. During my examination of her, she took a fit. There was no cry, wut otherwise the seizure was identical with an epileptic fit. I at once administered quarter of a grain of Morph. Sulpn. and gave a copious soap and water enema. The bowels, which were heavily loaded, moved/ 
moved very freely in about ten or fifteen minutes. About an hour later, I gave a large injection of saline solution per rectum. A large quantity of urine was passed involuntarily in about 20 minutes. There had been no fits since the hypodermic injection of morphia. The patient was sleeping heavily and her breathing was very stertorous. There were no signs of commencing labour. The patient remained in the same condition until about $2 \mathrm{a} \cdot \mathrm{m}$. when the fits retumed. I saw the patient shortIy aiterwards. I found labour in progress and patient in constant fits. Indeed, she never seemed properly out of one berore going into another. Labour terminated a few minutes arter my arrival, and there was pretty free haemorrhage, althougn not in any way alarming. The foetus, about seven and a half months, was dead. I administered a hypodermic injection of $\frac{1}{4} \mathrm{gr}$. Sulphate of Morphia just before labour set in. AIter labour, patient lay deeply comatose. It was quite impossible to rouse her and her pupils were contracted and did not appear to react to light. Her conjunctival reflexes were gone. Her pulse was very weak and thready, and her condition was most critical. I again gave her a very copious injection of saline solution/ 


\section{6.}

solution per rectum. Avout twenty minutes afterwards, there was a very large quantity of urine passed involuntarily.

The patient lay throughout the day in the same unconscious state. It was impossible to rouse her and her breathing continued stertorous and I found in the evening that her respirations were 40 and her pulse 140 and very weak. She had developed a peculiar short cough and a gurgle in her throat. Her temperature was subnormal and she appeared to be dying. About two hours later, or twenty-four hours aster her first fit, I was hurriedly summoned and found she had had another fit, which her motrier told me had been one of the severest and most prolonged. I found blood welling up very freely from her throat. This was frotiny and of a bright scarlet colour, evidently a vessel had been ruptured in ner lung. Her condition was now most critical and a fatal termination seemed only a question of time. I did not think it advisable to make a minute examination of the chest. I gave her a hypodermic injection of $\frac{1}{n} \mathrm{gr}$. sulphate of morphia. During the night she lay in an unconscious condition, blood coming up in the early part of the nignt pretty freely. But towards. moming the quantity diminished steadily. The coma/ 
coma also showed signs of abating and by pressing firmly on the supra orbital nerve, the patient could be roused. I was now able to examine the lungs and I found very marked duiness over the base of the right lung. The breathing was bronchial in type and there were abundant expitations. In the evening, about forty-eight hours from the time of the first fit, the respirations had fallen to twenty-five and the pulse was 100 beats per minute. The patient could now be roused and it was possible to get her to swallow some milk; but as soon as she was allowed to do so, she dropped off to sleep. The gurgle in her throat continued, but gradually disappeared. Some hours later it was possible to get her to answer questions, although onjy in a dreamy sort of way, and she had of course no recollection of what had happened. For about a week she continued coughing up blood; this gradually diminished in amount. The physical signs at the right vase cleared up gradually. For the greater part of the week her mental condition was very confused; but she ultimately made a good recovery.

I have recently examined her (In March of this year/ 
48.

year). She is in good health and there are no prysical signs to indicate that anything was ever wrong in her lung.

IV. Foetal Complications:

1. Prolapse of Cord has been met with in one case. The mother was a strong heal thy multipara. When I was called to the case I found labour well advanced and on separating the labia I found the cord low down. The os was fully dilated and retracted over the child's head, which appeared to be small. I decided to apply forceps as there was pulsation in the cord and the child was therefore alive. While making my preparations the pains, which were now very severe, and almost constant, forced the cord out at the vuiva and the head buiged the perineum. Dy pressing behind the rectum with the tips of my fingers I was able to deliver the head and the body followed at once. The child was a very small one, wut evidently fuil time. The heart was beating distinctly, but slow and feevie, and there was no erfort at respiration. I at once proceeded to carry out Schultze's method of inducing respiration and in about twenty minutes respiration was fully estaulished and the child ul timately/ 
uitimately did well. The mother also made excellent progress and had a normal puerperium.

\section{Twins: I have met with twice.}

Case I. In Juiy 1900 I was called to see a woman in a neighbouring village, who was said to be in lavour. On my arrival I found the woman was in lapour, which was well adranced, the os being fully dilated and the foetal head almost on the perineum. I was much struck by the woman's size. The patient was a healthy multipara. She told me that in her previous six labours she had not called a doctor in, as she was so quick and her labours so easy that she did not require a doctor. On this occasion, however, she had been so long she thougint there must be something wrong. Sise had ween over forty-eight hours in labour when she sent for me. In former labours she had been able to work in the fields to within a few days of her confinements; but on this occasion she had not veen able to do so. And indeed, for the last three months she had felt very seedy. She also told me that at the sixth month she had had an "ill turm". Her breasts became painful and she had had considerable abdominal pain and she thought she was going to miscarry. She lay up for a few days and felt better, al thougn not in her usual vigorous health. 
On examination I found the os fully dilated, the head low down in the pelvis, and the membrane unruptured. I therefore ruptured the membranes; very shortly a healthy full time male child was borm. The iiquor amnii was excessive in amount. After tying the cord I found on vaginal examination that there was evidently another child, and I could Ieel the second bag of waters. Very shortly afterwards a.complete sac with placenta, and the first child's placenta was expelled. The colour of the membranes of the second sac at once attracted attention, being of a dirty yellow colour. I opened the sac and a quantity of dark coloured foul smelling fluid poured out, and I found in the sac a slightly macerated six months foetus. The skin was in placed peeled off and the tissues were lax and wi thout elasticity. The cord was of a greenish colour. The appearance of this foetus corresponded with the supposition that its death occurred at the time when the mother nad the "ill turn" which she spoke of. The placentae were vexy closely joined together, but were quite separate and distinct.

Case II. My second case of twins I have already/ 
already reierred to, the first child being transverse. The case is recorded on page 25.

3. On two occasions I have met with an anencephalus foetus. In both cases I thought I had to deal with a face presentation. Both specimens were exceedingly characteristic, the necks being short and the heads resting directly upon the shoulders. The eyes in tine upturned faces being very prominent. One was living when born and the heart continued to beat for twenty or thirty minutes. In both cases the bodies were otherwise well developed. 


$$
52 .
$$

\section{PART II.}

Being a Critical Review of tire cases recorded, and of the General Practitioners relations to Midwi fery.

It cannot be other than a helpful exercise in any department of life to pass in review our previous experiences; to sit down quietly and calmly and to study fairly our work accomplished must be of great value to us in our further acquaintance with surfering humanity. And as we pause, in the perpetual rattle of practice, and review the past, certain questions must arise. Have I conscientiously discharged my duty to this, or to that patient? Has my treatment been founded upon, and carried out in scientific methods? Is my success as a practitioner in midwifery due to constant effort to profit by the constant advances in obstetrical knowledge; or is it due to manner? So often we hear, if a man's attainments in this branch of our profession are discussed, that it is all a matter of a pleasing manner. And in reviewing our own position we must in faimess measure it by the standards applied/ 
plied in discussing the position of others. In considering as a whole the cases recorded above, a mere superficial bird's eye view is sufficient to establish certain facts. In the first place we see that, excluding forceps cases, but including a case of puerperal insanity, al though the. 1 abour was a normal one, only twenty cases have called for special consideration. In other words, only four per cent of the total number. The remaining ninety-six per cent. were normal labours, some no doubt forceps cases, but still normal labours. If we exclude the twenty cases referred to, four hundred and eighty cases were vertex presentations, and only the first and second vertex positions were met with. In any other branch of medicine with so small a percentage of abnormal, or out of the way cases, a practitioner would get on very well with only a rough knowledge of them, as he could always send the case to hospital or get a consultant. In midwifery a general practitioner must be an expert, and be prepared to act and that quickly should any complication arise. In cases of placenta praevia, for example, a practitioner cannot send for assistance. Al though I have lately had a case brought under my notice where/ 
where a practitioner in a neighbouring village having diagnosed placenta praevia, in a case he had been called to, wired for assistance, and sat dow and waited with his patient until his colleague drove out the fifteen miles and delivered the case for him. Such a case of want of confidence is exceptional, and the requirements of country practice necessitate that medical men, so situated, must be conversant with all the complications which may occur, however rare.

It may further be noted that no case of puerperal infection has occurred in my own cases, and I am confident that this result has been obtained by following out in every case, the principles of which I learned the great importance, during my term of office as House Surgeon in Mr Cotterill's Wards of the Royal Infirmary in Edinburgh. I shall have to refer to some of the details later in carrying out safe methods in private practice, to which I consider sufficient importance is not given at the present time.

In reveiwing the cases in which it was necessary to apply forceps, certain facts at once strike one. In the first place, if these cases fairly/ 


\section{5.}

fairly represent those of the average general practitioner, we see that the anaesthetic must be given, and the forceps applied wi thout assistance, often with only a neighbour present, who has perhaps never seen a confinement before, except her own, or at most has only seen two or three. Is it to be wondered at then that many practitioners do not succeed in keeping their cases aseptic? As regards my own procedure in forceps cases, I always boil my Schimmelbusch's mask wi th my instruments. I cover it with white surgeons' lint and in this way I obtain a mask which I can handle with safety and then take hold of my forceps with little risk of infection. In working single handed it is a great advantage to draw the patient's hips well over the edge of the bed, so placing her body across the bed that it lies at right angles to the side of the bed upon which the surgeon is working., the thighs being well flexed upon the abdomen. The procedure I follow then is, after placing the patient in position.

First, after cleansing the hands, cleanse the extemal genitals, washing very thoroughly the area round about, well over the inner surfaces of the thighs, the mons veneris, and skin of the lower part/ 
56.

part of the abdomen, and round the rectum, which if necessary has been previously thoroughly evacuated by a copious enema. This careful and extensive washing is in my opinion of the very greatest importance. In applying forceps ones hands often come in contact with the patient's thighs and it is only consistent with our present theories that our hands should only come in contact with what is surgically clean. Having carefully washed these parts I wash them again with some antiseptic solution. As a rule 1 in 500 corrosive solution made from Burroughs and Wellcomes Soloids. Having accomplished this I administer chloroform and place the patient under. I then again wash my own hands and proceed to apply the forceps. If the patient has been put deeply under in the first instance there is ample time to render one's hands sterile and apply the forceps before it is necessary to reapply the mask. This may be done by the neighbour who is in attendance, the physician of course keeping an eye on the case himself. After the forceps are once applied, little chloroform is required to keep the patient under sufficiently during delivery.

In the case of patients where it is not necessary/ 
essary to apply forceps I follow very much the same procedure but I do not'wash the surrounding parts so extensively.

The frequent occurrence at the present time of symptoms, during the puerperium, indicating that septic infection has taken place at the time of labour in cases attended by general practitioners, is much to be deplored. The late Dr Milne Murray in his presidential address to the Edinburgh obstetrical Society drew attention to this matter and speaks of "the ridiculous parody which, in many practitioners hands, stands for the use of antiseptics." Dr Milne Murray again drew attention to this "melancholy fact" in a later address. On reading through a recent edition of an American textbook on Obstetrics, the following passage fixed my attention. "The hospital is now the safe place for a woman to be delivered in; it is in private dwellings that the danger lurks. The poorest, the dirtiest, and the most dissolute of women are safely confined in a lying-in hospital; the richest, the youngest, the purest, and the loveliest sometimes succumb in giving birth to a child in their own homes. In the private obstetric/ 
ric practice of the writer there is neither death nor sickness referable to infection, while in consultation practice he frequently sees death follow child birth or abortion. What is the cause of the difference? It is only that the writer uses strict antisepsis and that many general practitioners do not."

Reading a little further in the same textbook, we find, "Country practitioners are still greater opponents of antiseptic midwifery than their professional brethren in the cities, the country practitioner relying on the purity of the atmosphere in which he works and on the robust constitution of his patients."

The above quotations cannot be otherwise than painful reading, and give ample thought to general practitioners, and especially to those of us who practise in the country. In the first place, do these quotations really state fairly the facts of the case? Is the general practitioner such an unmitigated curse from an obstetrical point of view?

To any man who has really studied the question, it is very evident that the condition of affairs is even worse than that pictured. The fact/ 
fact that such statements pass unchallenged must be taken as proof that they are accepted by general practitioners as in the main correct. And in that part of my thesis dealing with antiseptics my object will be to show the difficulties to be met with in general practice in carrying out the details of antiseptic or aseptic methods, and to show the methods which I myself adopt, and in proof of their efficiency to submit the fact that they have enabled me to conduct 500 labours without a single case of sepsis. It is not too much to say that the average general practitioner in country districts has very few midwifery cases which are not to some extent septic. And I have formed this opinion in the main, from observations during periods when acting as locum tenens for country practitioners when I had to attend patients in their puerperium who had been attended in their confinements by the doctors for whom I acted, and I found almost invariably that there was slight rise of temperature and foul lochia. Within the last three years I have seen a number of cases with doctors in neighbouring villages, all more or less septic. All were cases where forceps had been applied/ 
applied on turning or manual removal of the placenta had been found necessary.

The quotations I have referred to make no mention of cases where the patients after their puerperium remain often for long periods in a debilitated and weakly state of health, as a result of prolonged septic processes. The death rate from puerperal fever is sufficiently appalling, but when we add to that the number of cases which become gynaecological as a result of septic processes, we are completely staggered. That this should be so is exceedingly unfortunate, because "the poorest, the dirtiest, and the most dissolute of women" are constantly confined in theix own homes in the Extern practice of the Rotunda, with a minimum percentage of septic cases. And we have to remember that they are mostly attended by undergraduates, or those who have very recently taken their degrees and who cannot therefore be looked on as experienced. After my own experiences in private practice I have no hesitation in saying that the results can be made just as good as those of any lying-in hospital. I have perfect confidence in making this statement, because all my early cases were/ 
were among the very poor; and therefore I can speak with some authority on midwifery practice among the "poorest, dirtiest and most dissolute of women". But if we pass from midwifery and glance for a moment at the general practitioners' results in minor surgery, we find his results in this department of his profession equally poor. His hands are washed neither before nor after opening a whitlow, and he may then remove a toe nail or an epithelioma with the sane instruments, which have not even been thoroughly washed, merely rinsed in warm water. His next case may be a midwifery case. How then can we wonder when puerperal fever develops?

It seems to me that too little importance has been given to what Kocker calls abstinence from risk of infection. Medical men do not realise their responsibility in this matter. It may not be possible for a doctor in practice to avoid contact with infective material, as he must constantiy be operating on cases of empyaema, disease of bone, and other conditions where septic organisms abound; but if he cannot avoid making his hands a storehouse for these organisms, then he should certainly leave midwifery to others.

There seems to have grown up a tendency to regard/ 
regard antiseptic midwifery as something distinct and apart from antiseptic surgery. But this is unfortunate. Aseptic and antiseptic midwifery are in no sense separate and distinct, and should not be divorced from aseptic and antiseptic surgery; it is merely the fundamental principles of the same system, applied with some modifications to meet the requirements of a special branch of surgery . It follows also that sepsis in midwifery is very much the same thing as the sepsis known in ordinary surgery, with certain of its own characteristics, derived from the situation of the septic wound or wounds in the parturient canal. Consequently any practitioner accustomed to operate by methods which enable his wounds to heal up by first intention carrying out such methods in his midwifery practice, cannot have other than the most successful results. Dr sniyly, in his term of mastership at the Rotunda often said he hoped he would live to see the day when the preparations for a vaginal examination during labour would be as carefully carried out as the preparations for an abdominal section.

Certain points are of so obvious importance that it seems strange that they are rarely mentioned The/ 
The first is the care of the hands. Every surgeon of experience must recall cases where a most modem man, taking every precaution which scientific investigation can suggest, has uniformly septic results. It is difficult often to point to any definite error in his procedure, but the cause will be found I think at 2.11 events, in many such cases in his neglect of the care of the hands. In applying modem methods of hand cleasing for surgical work we too often forget the importance of attending to the hands between operations. We forget in our daily ablutions that as it is unnatural for the hands to be constantly in strong lotions, we must use some emolient to keep the skin smooth and pliable. A good illustration of the importance of this is to be found in some gynaecological cases which became slightly septic at the Rotunda. The cases were all abdominal sections and the septic condition was Iimited entirely to the superficial wound. The matter gave the master and his assistants very anxious thought, every case operated upon was slightly septic. There was no great harm done, only the wounds were not healing by first intention, as they ought to. It should be explained. that/ 
that the assistant masters take it in rotation to be on duty in the Gynaecological Wards, going on month about. The assistant master who happened to be on duty was a most modem and energetic man in the application of antiseptics to the cleansing of his hands. He washed longer and soaked his hands longer in strong antiseptic solutions than any one. In talking the matter over with him, I pointed out that his hands were terrible hacked and that each little hack was a little testtube provided by nature fom the growth of bacteria. The irritation of his strong solutions ensured that his cracks were always full of a little serum, and as he took no precautions throughout the day to keep his hands free from infection, they were teeming with bacteria. Arrangements were accordingly at once made and he went off duty for the time being, and devoted himself to the treatment of his hands with emolients, etc. None of the cases afterwards showed any signs of infection and no other cases occurred after this assistant master returned to duty .

In a country practitioner's life there are many influences at work tending, to roughen the hands/ 
hands and there are very many occasions when the hands may become infected. It is therefore a matter of primary importance to devote considerable time to the care of the hands and the avoidence of risk of infection. The first object is attained by careful drying of the hands, especially in frosty weather, and by the use of some emolient cream. The second is best attained by the use of rubber gloves in operating upon all very septic cases, and in the use of ordinary "gloves" between operations.

There is one other point of great interest and importance. Some skins are much more easily cleaned than others. Some skins are naturally oily and antiseptic run off too easily. If a practitioner has unfortunately such a skin, he must devote still greater care to his hands and their cleansing.

The sterilisation of instruments in private practice is a matter requiring some consideration. What is the best method to adopt? Our instruments must be boiled. The question arises, are we to boil our instruments before going to a case, or is it better to carry a portable sterilizer and boil our instruments at the patient's house just before/ 
before use. The latter method has certain objections which we soon find on trying to carry such a method out. In the large proportion of our cases we have so little room that we must take as little as possible. In a two roomed cottage we have often difficulty in getting room for a basin to wash our hands in, and even if there is a table to place our steriliser upon, there is no room for it. Personally, I gave up this method at a very early date. And I now use a combined instrument and aressing sterilizer, the pattem being that de vised by Schimmelbusch. When I return from a case I at once turn out by bag and boil my instmiments. In my earlier cases I used an ordinary leather lined bag, which I sponged out with I in 20 carbolic solution. I now use a bag with a removable lining. This can very easily be sterilised. After sterilising my instruments, I put them away in my instrument cabinet and they are ready for use. When I am called to a case I have merely to wrap them up in one of several sterilised cloths which I al ways keep ready for the purpose. At the case I place them in a ewer with solution of carbolic, lysol, or creolin. It is/ 
is exceedingly important in the country to have everything so arranged that you can turn out at once, and if you arrive home to find a message to go to a confinement and a number of patients in your waiting room to be seen, and your instruments to boil, the sterilisation is not likely to be sufficiently thorough.

It will at once be realised that overwork in country practice will tend to interfere with thoroughness in carrying out the system sketched above. It is no easy matter to arrive home about I a.m., and proceed to clean and sterilise one's instruments, yet one must be ready to turm out at 3 a.m. if called upon, and confinements have a bad habit of coming all on a heap.

I am inclined to think that the poor results obtained in private practice are due chiefly to lack of thoroughness in carrying out details, often on account of over work. In certain districts over work and inadequate remuneration form the chief causes of the present frequency of septic cases in general practice. Club practice is generally regarded as a curse to our profession, but that it is a curse to those who think they benefit by it is not now realised. In certain of the iron districts near/ 
near Glasgow, the club doctor receives a fee of 5s. per confinement from the wives of members of the clubs. They cannot expect to get much for that, and verily they do not.

The frequency with which forceps should be applied is a favourite one for discussion at meetings of medical societies. If the majority of one's patients are of the agricultural class the forceps will rarely be required. And the small number of forceps cases in my series of 500 labours is due to the fact that the majority of the women I attended belonged to this class.

There has grown up a tendency among general practitioners to make too light of the dangers of forceps. I have the percentage of four of my colleagues. They are 10 per cent., 12 per cent., 13 per cent., and 30 per cent. For a district where labours are very easy and the women as a mile healthy, I cannot help thinking all are too high. Probably the most interesting of my cases are the series of eclampsia cases. The fourth and fifth cases are of special interest. Within the same Villiage a case of eclampsia occurred within a stone's throw of the house in which my patient Iived/ 
68.

lived and two other cases occurred during that same week about three miles away. One could not help thinking that atmospheric conditions must take some part as exciting causes. During the week the weather had been exceedingly sultry.

The occurrence of pulmonary haemorrhage during one of the eclamptic seizures is of very great interest and I have not in the literature on the subject seen any reference to such a complication. Bleeding has been strongly recommended in cases of eclampsia, but the possibility of the patient losing blood through a channel which we could not control. must be bome in mind. This case is also of unusual interest on account of its being the third attack, eclamptic fits having been observed in two previous pregnancies.

As regards the treatment adopted, the very rapid effect of the hypodermic injection of morphia have to be noted. At the same time the very marked increase in the depth of the coma must be noted. The very rapid and free diuresis which followed the saline injection per rectum is also of great interest.

It is a difficult matter to lay down any hard and/ 
and fast mies regarding the best treatment to adopt in cases of eclampsia occurring in country practice. Preventive treatment should of course be adopted in any pregnant woman who has albuminuria, oedema, deficiency of urine or a pulse of high tension. Unfortunately in the country, women usually only send when they are in labour. Rapid dilatation and delivery seems at the present time easily accomplished, the dilatation being safely carried out by Boca's dilator. A considerable number of cases having been recorded.

Treatment by thyroid extract appears to be almost a specific and I have not been able to find a report of any case in which it failed. 
70.

\section{A P P E N D I X.}

To those of us who have been drilled from our earliest student days in antiseptic and aseptic methods, it is a source of much satisfaction to feel that it is possible to conduct our confinements wi thout risk of infection. If a deeply rooted love of country life makes a man choose what at first sight seems a less interesting professional career, he has ample reward when he finds his maternity patients making swift recoveries. Whatever the disadvantages may be, there cannot be other than a thrill of pleasure in taking the stitches out of an operation wound (e.g. in a case of strangulated hermia) at the first dressing, on the tenth day, or in watching a woman pass through her puerperium with a, normal temperature.

Among the disadvantages of country practice we must number the impossibility of carrying on systematic study. The nature of one's work entails constant interruptions, and it is only when in full harness that one realises that a country doctor is the servant of the general public. And. the/ 
the general public is a hard master. Many years ago, when uncertain where to settle, I met an old doctor. A typical example of the old school. He gave me much advice out of his rich experience. One thing above all he impressed upon me, to take up some branch of medicine and endeavour to make myself a specialist in it. During the last five years I have endeavoured to follow out this idea. And wi th this object ever before me, I have spent at least a few minutes each day in studying works on Obstetrics and in the time I have systematically studied the following text-books and manuals:

"Science and Practice of Midwifery", Playfair.

"Science and Art of Midwifery", Lusk.

"Contributions to Obstetrics and Gynaecology", Professor A. R. Simpson.

"Manual of Midwifery", Eothergill.

"Difficult Labour", Herman.

"A Manual of Midwifery", Gelabin

"A Short Practice of Midwifery", Jellet

"Abdominal Manipulation in Pregnancy", Mactennan. 
Papers, etc., referred to and consulted in preparation of Thesis.

Presidential Address, Dr James Ritchie, Edin. Med. Journal, Vol.XII., p.580.

The Late Dr Milne Murray's Address, Edin. Med. Journal, Vol.IX., p.30

Dewar, "The Use and Abuse of Forceps in General Practice." Trans. Edin. Obstetrical Soc., Vol.XXVII., p.212.

Discussion on Puerperal Insanity, Obstetrical Society of London, "Lancet" Vol.I., 1903, p.239

Kerr, "Eclampia, An Analysis of cases in Glasgow Maternity Hospital in last 15 years. Glasgow Hospital Reports, 1901.

Berkeley, "The Treatment of Eclampsia" Journal

of Obstetrics and Gynaecology, Vol. V., p.263

Herman, Allbutt's System of Medicine, Vol.VII., p.797.

Jardine, Brit. Med. Journal, March, 1900.

Jardine, "The Treatment of Puerperal Eclampsia by saline diuretic Injections, based on 22 cases." International Clinics, Vol.II., 1Ith series.

"The Antiseptic Treatment of Wounds." Schimmelbusch.

"Treatment of Wounds, Abscesses and Ulcers." Watson Cheyne.

"Aseptic Surgery" Lockwood.

"Abstinence from Risk of Infection" Kocker, p.29

"Hand Disinfection", Purves. Edin \& Med. Journal, Vol.SIII. p.3I5

"The Prevention of Septic Infection" during Labour during Labour and the Puerperium." Jardine: Journal of Obstetrics and Gynaecology - Narch 1904.

"Puerperal Sepsis". Horrocks, Brit. Med. Joun. February, 1904. 
73.

"Suppuration and Septic Diseases." Watson Cheyne. 